\title{
РАБОЧЕГО СТОЛА
} СОЦИОЛОГА

\section{From THE WORKING TABBL OF A SOCIOLOGIST}

\section{ЦЕННОСТНАЯ ТРАНСФОРМАЦИЯ СОВРЕМЕННОГО БЕАОРУССКОГО ОБЩЕСТВА (ПО РЕЗУАЬТАТАМ СОЦИОАОГИЧЕСКИХ ИССАЕАОВАНИЙ)}

\author{
И. В. ЛАШУК ${ }^{1)}$ \\ ${ }^{1)}$ Белорусский государственный экономический университет, \\ nр. Партизанский, 26, 220070, г. Минск, Беларусь
}

Представлены результаты исследования структуры базовых ценностей белорусского общества, полученные при использовании методики построения функционально-ориентирующих кластеров базовых ценностей Н. И. Лапина. Выявлены ценности, которые обеспечивают интеграцию населения Беларуси, а также опосредуют включенность индивида в жизнеобеспечивающие, властно-политические и социокультурные структуры общества. Проведен анализ степени поддержки респондентами базовых ценностей, сгруппированных по их принадлежности к терминальным (ценности-цели) либо инструментальным (ценности-средства) ценностям и в соответствии с социокультурными ценностями (традиционные, современные, общечеловеческие). Выявлено, что устойчивым интегрирующим ядром базовых ценностей белорусского общества являются жизнь человека и порядок. Признание ценности и неприкосновенности человеческой жизни занимает доминирующую позицию в иерархии базовых ценностей белорусов. Высокий уровень поддержки ценности порядок свидетельствует о большой значимости для белорусского общества стабильности и организации социальных отношений, сформированных на основе соблюдения установленных законов

Образец цитирования:

Лашук ИВ. Ценностная трансформация современного белорусского общества (по результатам социологических исследований). Журнал Белорусского государственного университета. Социология. 2021;1:90-99. https://doi.org/10.33581/2521-6821-2021-1-90-99
For citation:

Lashuk IV. Value transformation of modern Belarusian society (as results of sociological research). Journal of the Belarusian State University. Sociology. 2021;1:90-99. Russian.

https://doi.org/10.33581/2521-6821-2021-1-90-99

\begin{abstract}
Ав тор:
Ирина Валерьевна Лашук - кандидат социологических наук, доцент; заведующий кафедрой экономической социологии и психологии предпринимательской деятельности Института социально-гуманитарного образования.
\end{abstract}

\section{Author:}

Iryna V. Lashuk, PhD (sociology), docent; head of the department of economic sociology and psychology of entrepreneurship, Institute of Social Science and Humanitarian Education.

lashuk@bseu.by 
и норм. Однако средства их достижения изменились за счет повышения важности нравственного выбора, выражающегося в возможности помочь нуждающимся даже в ущерб себе, и инструментальной ценности властность, проявляющейся в стремлении оказывать влияние на других людей. Сопоставляются результаты исследований ценностей для белорусского общества, проведенных в 2017 и 2020 гг. За счет падения востребованности традиционных и современных ценностей в 2020 г. произошел серьезный рост значимости общечеловеческой группы ценностей, при этом как и в 2017 г., терминальные ценности опережают по важности инструментальные. Среди ценностей-целей приоритетными для населения в 2020 г. были жизнь человека, порядок и свобода; среди ценностей-средств - жертвенность и властность. С целью изучить вариативность ценностной структуры сравнивались базовые ценности в разных возрастных группах населения. Межпоколенческий аксиологический анализ показал, что вне зависимости от возраста интегрирующими компонентами являются жизнь человека и порядок. При этом в молодежной когорте в интегрирующее ядро вошла также ценность свобода.

Ключевые слова: базовые ценности; терминальные и инструментальные ценности; социокультурные ценности; функционально-ориентирующие кластеры.

Благодарность. Автор выражает благодарность научному коллективу Центра социально-гуманитарных исследований учреждения образования «Белорусский государственный экономический университет».

\title{
VALUE TRANSFORMATION OF MODERN BELARUSIAN SOCIETY (AS RESULTS OF SOCIOLOGICAL RESEARCH)
}

\author{
I. V. LASHUK ${ }^{\mathrm{a}}$ \\ a Belarus State Economic University, \\ 26 Partyzanski Avenue, Minsk 220070, Belarus
}

The article presents the results of the study of the structure of the basic values of the Belarusian society using the method of constructing functional-oriented clusters of basic values by N. I. Lapin. The values that ensure the integration of the population of Belarus as a whole, as well as mediate the inclusion of the individual in the life-supporting, power-political and socio-cultural structures of society, were identified. The analysis of the degree of respondents' support for basic values, grouped on additional grounds: according to their belonging to terminal (values-goals) or instrumental (values-means) values, and in accordance with cultural types of values (traditional, modern, universal values). It is revealed that the stable integrating core of the basic values of the Belarusian society are the values of human life and order. The recognition of the value and inviolability of human life occupies a dominant position in the hierarchy of basic values of Belarusians. The high level of support for the value of order indicates the great importance for the Belarusian society of stability and the organisation of social relations based on compliance with established laws and norms. However, the means of achievement have changed due to the increased importance of moral choice, which is expressed in the ability to help other people in need, even to the detriment of themselves, and the instrumental value of power, which is manifested in the desire to influence other people. A comparative analysis by year shows that in 2020 there was a serious increase in the importance of the universal group of values due to the decline in the demand for traditional and modern values. As in 2017, terminal values are more significant than instrumental values. Among the values-goals, the greatest support of the population in 2020 is human life, order and freedom; among the values-means - sacrifice and power. In order to study the variability of the value structure, a comparative study of the basic values of different age groups of the population was carried out. The intergenerational axiological analysis showed that in all age groups the integrating components are human life and order. At the same time, in the youth cohort, svoboda also entered the integrating core.

Keywords: basic values; terminal and instrumental values; sociocultural values; functional focusing clusters.

Acknowledgements. The author expresses gratitude to the research team of the Center for Social and Humanitarian Research of the educational institution «Belarusian State Economic University».

В социологии одно из центральных мест принадлежит проблеме ценностей. Разработкой понятия ценностей занимался еще Э. Дюркгейм, который для их объяснения в своих работах применил социологический подход. Мыслитель, с одной стороны, признавал трансцендентный характер ценностей, а с другой - считал, что само общество выступает не только как эмпирическая, но и в значительной мере как трансцендентная и сакральная реальность, источник и вместилище всех высших ценностей, ко- торые доступны и подлежат научному описанию и объяснению. В конечном счете даже самые высокие ценности, с точки зрения Э. Дюркгейма, основаны на реальности и проистекают из нее.

Подчеркивая роль ценностного аспекта социальной регуляции, ученый пришел к выводу, что в нормальных условиях внешняя социальная детерминация осуществляется через ценностные ориентации индивидов. Должное и желаемое, нормы и ценности в таком истолковании оказываются двумя сто- 
ронами одной медали. Социальные нормы эффективны только в том случае, когда они опираются на нравственный авторитет общества, а не на внешнее принуждение.

Проблема ценностей стала одной из актуальных в социологии благодаря М. Веберу, который вывел понятие ценности в разряд ключевых. Ценностнорациональное является одним из четырех типов социального действия и определяется осознанной верой в ценность какого-либо действия независимо от его успеха. Ценность, по мнению ученого, - это форма человеческого мышления, способ умозаключений, ее нельзя охарактеризовать в категориях положительная - отрицательная, относительная - абсолютная, объективная - субъективная и т. п. Ценность, или значимость, есть также соотношение между человеком и миром вещей, людьми и духовными явлениями. Она напрямую не связана с утилитарным назначением этих вещей и событий, практической пользой. Носителем ценностей является личность, постигающая их в опыте внутреннего принятия или отталкивания. Место данных ценностей в мотивации действий гораздо глубже целей и интересов. Именно отнесение к ценности как к приданию смысла, на основе которого формулируется цель, указывает на самое главное, что определяет поведение человека. М. Вебер, в отличие от Э. Дюркгейма, считал, что ценности находятся по ту сторону эмпирической реальности, не сводимы к ней и могут быть предметом лишь веры, но не научного познания.

Социальные ценности как элементы системы общества наиболее полно рассмотрены в работах T. Парсонса, который определял свою теорию социального действия как концептуальную схему для анализа поведения живых организмов, поведения, которое ориентируется на достижение цели и ценностно-нормативно регулируется. Действия акторов, по Парсонсу, объединены в системы действия (социальную, культурную и систему личности). В своей теории ученый делает акцент на первичности ценностно-нормативной системы общества по отношению к индивиду, на приоритетности социального консенсуса, стабильности и недопущении конфликтов в обществе.

В социологии в рамках противоположной парадигмы также присутствует интерес к ценностной проблематике, поскольку существует особый тип социального конфликта - ценностный конфликт. Он может протекать на разных уровнях: внутриличностном, межиндивидуальном, межгрупповом, межинституциональном, межкультурном и межцивилизационном. Ценностные конфликты происходят в условиях ограниченности социальных благ, часто отражают глубинные процессы, возникающие в обществе.
В настоящее время отечественные и зарубежные социологи активно занимаются теоретическими и практическими разработками в области аксиологии. Накоплен обширный материал, посвященный различным подходам к изучению проблемы ценностей.

Белорусские социологи также уделяют большое внимание ценностным трансформациям современного общества. Так, А. Н. Данилов рассматривает основные результаты системной трансформации в странах постсоветского мира, особенности их интеграции в условиях глобального финансового кризиса, прогнозирует контуры нового мирового порядка [1]. Вопросами социального устройства активно интересуется С. А. Шавель [2]. Д. Г. Ротман и другие мыслители активно изучают ценностный мир современного человека и общества [3]. Анализируются процессы модернизации системы высшего образования Республики Беларусь в работах Л. Г. Титаренко [4].

На сегодняшний день большинство эмпирических исследований ценностей в той или иной степени основываются на методике Рокича, которая базируется на прямом ранжировании их списка. Ученый различает два класса ценностей: терминальные (убеждения в том, что конечная цель индивидуального существования стоит того, чтобы к ней стремиться (набор из 18 ценностей)); инструментальные (убеждения в том, что какой-то образ действий или свойство личности является предпочтительным в любой ситуации (набор из 18 ценностей)).

Это деление соответствует традиционному делению на ценности-цели и ценности-средства.

Достоинством методики является универсальность, удобство и экономичность в проведении исследования и обработке результатов, гибкость, т. е. возможность варьировать как диагностический материал (списки ценностей), так и инструкции. Существенный недостаток данной методики проявляется во влиянии социальной желательности, возможности неискренности.

Ценность определяется М. Рокичем как устойчивое убеждение в том, что определенный образ поведения или конечного состояния для индивида или общества предпочтительнее, чем противоположный образ поведения или конечного состояния. Необходимо отметить, что сведение ценности к предпочтению ограничивает понимание данного феномена, не учитывает его специфических особенностей, природы и сущности.

Феномен ценности, согласно концепции Рокича, функционирует в действительности в качестве устойчивых убеждений относительно предпочтительного образа поведения, которые он именует инструментальными ценностями, или ценностямисредствами (образованность, высокие запросы, не- 
зависимость, ответственность, рационализм, самоконтроль и др.), а также в качестве устойчивых убеждений относительно предпочтительного образа конечного состояния, названных им терминальными ценностями, или ценностями-целями (здоровье, интересная работа, любовь, материально обеспеченная жизнь, наличие друзей, общественное признание, свобода и др.).

Из всего вышесказанного следует, что методика Рокича является признанным и популярным инструментом изучения ценностей. Многие современные исследователи ценностной проблематики либо применяют ее в оригинальном виде, либо создают ее адаптированные варианты, либо используют некоторые ее методологические основания.

В настоящее время эмпирико-социологический подход не ограничен методикой Рокича, а представлен различными методами изучения ценностей и ценностных ориентаций. По этой причине перед социологами, занимающимися вопросами аксиологии, ставится задача как классификации, так и выделения наиболее адекватных методов и методик их измерения.

Таким образом, в области изучения ценностей разработано достаточно большое многообразие методик. Также существуют и другие методики, которые основаны на использовании как количественных, так и качественных приемов ${ }^{1}$.

Фокус внимания в настоящей работе сосредоточен на изучении ценностных приоритетов белорусского общества в контексте их (ценностей) дифференцирующих и интегрирующих функций. Представленное научное исследование построено на основе типовой методики всероссийской про-

граммы «Проблемы социокультурной эволюции регионов России», разработанной Центром изучения социокультурных изменений Института философии Российской академии наук (руководители Н. И. Лапин, Л. А. Беляева). По мнению автора настоящей статьи, на современном этапе общественного развития рассматриваются две основные формы социокультурной трансформации:

«1) традиционализация - возникновение институционализации традиций, других элементов культуры и социальной структуры, которые обеспечивают приоритет предписанных норм и правил поведения субъектов (традиционных действий) по сравнению с возможностями их инновационных действий; 2) либерализация (модернизация) расширение свободы выбора и ответственности субъектов, увеличение возможностей для инновационных целерациональных действий путем дифференциации структуры общества, возникновения и включения в нее новых интегрирующих элементов. <...> Либерализация апеллирует к ценности свободы и сопряжена с веберовской рационализацией исторического процесса» [5, с. 8].

В качестве эмпирической базы исследования использованы результаты двух социологических исследований: «Социокультурные механизмы и факторы консолидации белорусского общества» ${ }^{2}$ и «Социокультурный портрет современного белорусского общества» ${ }^{3}$. В соответствии с программой Н. И. Лапина в исследованиях представлено 14 ценностей (табл. 1), отражающих исключительно базовые ценности, которые автор дифференцирует на три группы: традиционные, общечеловеческие, современные (модернистские, либеральные) [6, с. 48].

$$
\text { Таблица } 1
$$

Методика изучения базовых ценностей Н. И. Лапина

Table 1

The method of studying the basic values of N. I. Lapin

\begin{tabular}{|l|l|}
\hline \multicolumn{1}{|c|}{ Ценности } & \multicolumn{1}{c|}{ Ценностные суждения } \\
\hline Нравственность & В любых условиях красота делает человека лучше и чище \\
\hline Благополучие & Главное в жизни - забота о своем здоровье и благополучии \\
\hline Своевольность & $\begin{array}{l}\text { Бывают обстоятельства, когда человек сам по своей воле может } \\
\text { посягнуть на жизнь другого человека }\end{array}$ \\
\hline
\end{tabular}

\footnotetext{
${ }^{1}$ Подробнее теоретические подходы к исследованию ценностей представлены в монографии: Лашук И. В. Социокультурный анализ современного белорусского общества. Минск : Беларуская навука, 2019. 267 с.

${ }^{2}$ Социологическое исследование «Социокультурные механизмы и факторы консолидации белорусского общества» (руководитель - И. В. Лашук), проведенное Институтом социологии НАН Беларуси в 2017 г. Выборочная совокупность репрезентативна по полу, возрасту, типу населенного пункта, уровню образования и региону проживания (1502 респондента).

${ }^{3}$ Социологическое исследование «Социокультурный портрет современного белорусского общества» (руководитель И. В. Лашук), проведенное Центром социально-гуманитарных исследований УО «Белорусский государственный экономический университет» по заказу БИСИ в 2020 г. Выборочная совокупность репрезентативна по полу, возрасту, типу населенного пункта, уровню образования и региону проживания (1500 респондентов).
} 
Окончание табл. 1 Ending table 1

\begin{tabular}{|l|l|}
\hline \multicolumn{1}{|c|}{ Ценности } & \multicolumn{1}{c|}{ Ценностные суждения } \\
\hline Свобода & Свобода человека - это то, без чего его жизнь теряет смысл \\
\hline Работа & $\begin{array}{l}\text { Только содержательная, интересная работа заслуживает того, } \\
\text { чтобы заниматься ею как основным делом жизни }\end{array}$ \\
\hline Порядок & $\begin{array}{l}\text { Личная безопасность человека должна обеспечиваться законом } \\
\text { и правоохранительными органами }\end{array}$ \\
\hline Общительность & $\begin{array}{l}\text { В жизни главное внимание нужно уделять тому, чтобы } \\
\text { установить хорошие семейные и дружеские отношения }\end{array}$ \\
\hline Властность & $\begin{array}{l}\text { Человек должен стремиться к тому, чтобы у него в первую } \\
\text { очередь была власть, возможность оказывать влияние на других }\end{array}$ \\
\hline Жертвенность & $\begin{array}{l}\text { Нравственный, совестливый человек должен помогать бедным } \\
\text { и слабым, даже если ему приходится отрывать что-то от себя }\end{array}$ \\
\hline Независимость & $\begin{array}{l}\text { Я стал таким, какой я есть, главным образом благодаря } \\
\text { собственным усилиям }\end{array}$ \\
\hline Инициативность & $\begin{array}{l}\text { Главное - это инициатива, предприимчивость, поиск нового } \\
\text { в работе и жизни, даже если оказываешься в меньшинстве }\end{array}$ \\
\hline Семья & \begin{tabular}{l} 
Люди и государство должны больше всего заботиться о детях \\
\hline Жизнь человека
\end{tabular} \\
\hline $\begin{array}{l}\text { Самое ценное на свете - это человеческая жизнь, и никто не } \\
\text { вправе лишать человека жизни ни при каких обстоятельствах }\end{array}$ \\
\hline Традиция & \begin{tabular}{l} 
Главное - это уважение к сложившимся обычаям, традициям \\
\hline
\end{tabular} \\
\hline
\end{tabular}

Используемая методика включает три этапа анализа.

На первом этапе произошло разделение изучаемых ценностей на два кластера:

- интегрирующий, включающий в себя верхний слой (так называемое интегрирующее ядро) и нижний (интегрирующий резерв);

• дифференцирующий, состоящий также из двух слоев: верхнего (оппонирующий дифференциал) и нижнего (конфликтогенная периферия). Оппонирующий дифференциал содержит нейтральные ценности. Они не являются отрицательными, но при этом не обладают значимой поддержкой со стороны населения. При эволюции ценностной структуры общества именно они могут стать новым значимым основанием интеграции общества. Конфликтогенная периферия включает ценности, которые фактически отрицаются большинством населения.

Второй этап изучения ценностной структуры представлен анализом иерархии базовых ценностей жизнеобеспечивающего, институционно-регулятивного и антропно-коммуникативного кластеров.

Жизнеобеспечивающий кластер ценностей опосредует отношение индивида к социально-хозяйственным институтам, реализующим функцию жизнеобеспечения как отдельного индивида, так и всего общества в целом. Институционно-регулятивный кластер объединяет ценности, которые имеют связь с властно-политической системой общества и предопределяют поведение людей в социуме. Антропно-коммуникативный кластер ценностей опосредует взаимосвязь человека с социальными и культурными структурами общества [7, с. 33-35].

Третий этап исследования базовых ценностей основан на использовании двух теоретических типологий. Первая типология ценностей (культурнотипическая) устанавливает принадлежность ценностей к определенному типу общества. В соответствии с ней выделяются традиционные, современные и общечеловеческие социокультурные базовые ценности. Их распределение в разных слоях интегрирующего и дифференцирующего кластеров позволяет определить, какие ценности обеспечивают интеграцию общества. Вторая типология ценностей основана на разделении ценностей на терминальные (фиксируют важнейшие цели в жизни, отражая убеждения человека в том, что конечная цель индивидуального существования стоит того, чтобы к ней стремиться) и инструментальные (закрепляют убеждения в том, что определенный образ действий личности является предпочтительным в любой ситуации).

Итак, используемая методика позволяет не только охарактеризовать структуру базовых ценностей белорусского общества, но и выделить ценности, способные стать в условиях социальных трансформаций новым интегрирующим фундаментом. Помимо этого, появляется возможность описать иерархию базовых ценностей, оказывающих влияние на отношение индивида к жизнеобеспечивающим, властно-политическим и социокультурным структурам общества. Анализ распространенности культурных типов базовых ценностей в дифферен- 
цирующем и интегрирующем кластерах способствует определению ценностного типа общества.

Сравнительный анализ социологических исследований, проведенных в 2017 и 2020 гг., позволил зафиксировать тот факт, что в интегрирующем ядре устойчиво сохраняются ценности жизнь человека и порядок. Именно они в наибольшей степени объединяют белорусов (табл. 2).

Таблица 2

Динамика базовых ценностей белорусского общества

Table 2

Dynamics of the basic values of the Belarusian society

\begin{tabular}{|c|c|c|c|}
\hline \multirow{2}{*}{\multicolumn{2}{|c|}{ Кластер }} & \multicolumn{2}{|c|}{ Год } \\
\hline & & 2017 & 2020 \\
\hline \multirow{7}{*}{ Интегрирующий } & \multirow{3}{*}{$\begin{array}{l}\text { Интегрирующее } \\
\text { ядро }\end{array}$} & Жизнь человека & Жизнь человека \\
\hline & & Порядок & Порядок \\
\hline & & Семья (родительство) & Общительность \\
\hline & \multirow{4}{*}{$\begin{array}{l}\text { Интегрирующий } \\
\text { резерв }\end{array}$} & Общительность & Свобода \\
\hline & & Благополучие & Жертвенность \\
\hline & & Свобода & Благополучие \\
\hline & & Независимость & Властность \\
\hline \multirow{7}{*}{ Дифференцирующий } & \multirow{5}{*}{$\begin{array}{l}\text { Оппонирующий } \\
\text { дифференциал }\end{array}$} & Традиция & Работа \\
\hline & & Работа & Традиция \\
\hline & & Нравственность & Семья (родительство) \\
\hline & & Инициативность & Инициативность \\
\hline & & Жертвенность & Нравственность \\
\hline & \multirow{2}{*}{$\begin{array}{l}\text { Конфликтогенная } \\
\text { периферия }\end{array}$} & Своевольность & Своевольность \\
\hline & & Властность & Независимость \\
\hline
\end{tabular}

Следует также отметить, что в 2020 г. интегрирующей ценностью стала общительность, а в интегрирующий резерв вошли жертвенность и властность. При этом независимость переместилась в конфликтогенную периферию.

Таким образом, устойчивым интегрирующим ядром базовых ценностей белорусского общества являются жизнь человека и порядок. Признание ценности и неприкосновенности человеческой жизни занимает доминирующую позицию в иерархии базовых ценностей белорусов. Высокий уровень поддержки ценности порядок свидетельствует о большой значимости для белорусского общества стабильности и организации социальных отношений, сформированных на основе соблюдения установленных законов и норм.

На втором этапе базовые ценности были перегруппированы в три кластера: жизнеобеспечивающий, институционно-регулятивный и антропнокоммуникативный. Наборы ценностей каждого кластера заранее определены, однако внутренняя структура данных групп может быть вариативной.

Жизнеобеспечивающий кластер объединяет ценности, которые определяют характер витальных потребностей человека. Этот набор ценностей формирует представление индивида о нормальном протекании жизни, а также способах его достижения.

В 2017 г. в данном кластере главная роль принадлежала таким ценностям, как семья, благополучие и независимость. По результатам социологических замеров в 2020 г. внутри кластера произошло переформатирование структуры. По сравнению с 2017 г. в 2020 г. значимость ценностей, входящих в жизнеобеспечивающую группу, понизилась, и первые ранговые места стали занимать ценности благополучие, работа и семья (табл. 3$)^{4}$.

Институционно-регулятивный кластер включает в себя ценности, которые выступают социокультурной основой существования социальных институтов и опосредуют одобряемые формы поведения индивидов в обществе. Доминирующими ценностями в этом кластере в 2017 г. выступали порядок, свобода и традиция; в 2020 г. - порядок, свобода и властность. Таким образом, можно говорить об устойчиво высокой значимости социальной стабильности, которая основывается на обеспечении личной безопасности и признании приоритетной важности свободы для жизни человека. Как в 2017 г., так и в 2020 г. своевольность - вовсе не-

\footnotetext{
${ }^{4}$ Значимость ценности определялась в интервале от 1 до 4, где 1 - абсолютное несогласие; 4 - абсолютное согласие.
} 
популярная ценность среди населения, поскольку по своему смысловому содержанию она противоположна социальной стабильности.

Антропно-коммуникативный кластер состоит из ценностей, опосредующих интеграцию человека в социальные и культурные структуры общества. В 2017 г. в структуре данного кластера преобладали ценности жизнь человека, общительность и свобода; в 2020 г. - жизнь человека, общительность и жертвенность. Это свидетельствует о том, что включение индивида в социальное и культурное взаимодействие устойчиво базируется на признании им человеческой жизни как наивысшей ценности и установлении тесных связей с близким кругом людей (семья и друзья).

На третьем этапе анализа базовые ценности были сгруппированы в соответствии с теоретической типологией Лапина, в которой каждый культурный тип ценностей включает как терминальные, так и инструментальные ценности (табл. 4).

Таблица 3

\section{Жизнеобеспечивающий, институционно-регулятивный и антропно-коммуникативный кластеры базовых ценностей, среднее значение}

Table 3

Life-supporting, institutional-regulatory, and anthropic-communicative clusters of basic values, average value

\begin{tabular}{|c|c|c|c|}
\hline \multirow{2}{*}{ Кластер } & \multirow{2}{*}{ Ценности } & \multicolumn{2}{|c|}{ Год } \\
\hline & & 2017 & 2020 \\
\hline \multirow{5}{*}{ Жизнеобеспечивающий } & Семья & 3,49 & 2,86 \\
\hline & Благополучие & 3,36 & 3,23 \\
\hline & Независимость & 3,28 & 1,88 \\
\hline & Работа & 3,04 & 3,01 \\
\hline & Инициативность & 2,96 & 2,76 \\
\hline \multirow{5}{*}{ Институционно-регулятивный } & Порядок & 3,52 & 3,48 \\
\hline & Свобода & 3,32 & 3,30 \\
\hline & Традиция & 3,09 & 2,86 \\
\hline & Своевольность & 1,90 & 2,12 \\
\hline & Властность & 1,91 & 3,22 \\
\hline \multirow{5}{*}{ Антропно-коммуникативный } & Жизнь человека & 3,68 & 3,68 \\
\hline & Общительность & 3,42 & 3,31 \\
\hline & Свобода & 3,32 & 3,30 \\
\hline & Нравственность & 2,95 & 2,45 \\
\hline & Жертвенность & 2,90 & 3,28 \\
\hline
\end{tabular}

Наибольшей поддержкой среди населения страны в 2017 г. пользовались современные ценности, а наименьшей - традиционные. Самыми значимыми являлись терминальные ценности по сравнению с инструментальными. В числе ценностей-целей на первое место население ставило жизнь человека, порядок и семью, а среди ценностей-средств - общительность и независимость.

Сравнительный анализ по годам свидетельствует о том, что в 2020 г. за счет падения востребованности традиционных и современных ценностей произошел серьезный рост значимости общечеловеческой группы ценностей. Предпочтение было отдано, как и в 2017 г., терминальным ценностям. Самыми главными среди ценностей-целей являлись жизнь человека, порядок и свобода, а в числе ценностей-средств - жертвенность и властность.

Таким образом, жизнь человека и порядок оказались достаточно стабильными ценностями, нахо- дящимися в приоритете у населения. Однако средство их достижения изменилось за счет повышения значимости нравственного выбора, выражающегося в возможности оказать помощь тем, кто в ней нуждается, даже в ущерб себе, и инструментальной ценности властность, проявляющейся в стремлении воздействовать на других людей.

По итогам социологического замера, проведенного в 2020 г., выявлены межпоколенческие различия в структуре базовых ценностей белорусов. Респонденты были распределены на три возрастные группы: 18-29 лет; 30-49 лет и 50 лет и старше. Сопоставив результаты анализа, следует сделать вывод о том, что молодое поколение, по сравнению с более старшими когортами, в большей степени ориентировано на своевольность, свободу и семью. С возрастом актуализируется значимость таких базовых основ, как порядок, общительность, инициативность, жизнь человека (табл. 5). 
Культурные типы базовых ценностей населения

Республики Беларусь, среднее значение

Table 4

Cultural types of basic values of the population of the Republic of Belarus, average value

\begin{tabular}{|c|c|c|c|c|}
\hline \multirow{3}{*}{$\begin{array}{c}\text { Социокультурные } \\
\text { ценности }\end{array}$} & \multirow{2}{*}{\multicolumn{2}{|c|}{ Год }} & \multicolumn{2}{|c|}{ Ценности } \\
\hline & & & \multirow{2}{*}{$\begin{array}{c}\text { Терминальные } \\
\text { (ценности-цели) }\end{array}$} & \multirow{2}{*}{$\begin{array}{l}\text { Инструментальные } \\
\text { (ценности-средства) }\end{array}$} \\
\hline & 2017 & 2020 & & \\
\hline \multirow{2}{*}{ Традиционные } & \multirow{2}{*}{2,85} & \multirow{2}{*}{2,78} & Семья & Жертвенность \\
\hline & & & Традиция & Своевольность \\
\hline \multirow{3}{*}{ Общечеловеческие } & \multirow{3}{*}{3,03} & \multirow{3}{*}{3,12} & Порядок & Общительность \\
\hline & & & Благополучие & Нравственность \\
\hline & & & Работа & Властность \\
\hline \multirow{2}{*}{ Современные } & \multirow{2}{*}{3,31} & \multirow{2}{*}{2,91} & Жизнь человека & Независимость \\
\hline & & & Свобода & Инициативность \\
\hline
\end{tabular}

Таблица 5

Структура базовых ценностей в разных возрастных группах, среднее значение

Table 5

Structure of basic values

in different age groups, average value

\begin{tabular}{|l|c|c|c|}
\hline \multirow{2}{*}{ Базовая ценность } & \multicolumn{3}{|c|}{ Возрастная группа } \\
\cline { 2 - 4 } & $18-29$ лет & $30-49$ лет & 50 лет и старше \\
\hline Нравственность & 2,49 & 2,48 & 2,40 \\
\hline Благополучие & 3,24 & 3,18 & 3,26 \\
\hline Своевольность & 2,31 & 2,12 & 1,99 \\
\hline Свобода & 3,42 & 3,28 & 3,25 \\
\hline Работа & 3,08 & 3,00 & 2,98 \\
\hline Порядок & 3,46 & 3,44 & 3,52 \\
\hline Общительность & 3,22 & 3,32 & 3,36 \\
\hline Властность & 3,05 & 3,20 & 3,36 \\
\hline Жертвенность & 3,23 & 3,28 & 3,30 \\
\hline Независимость & 2,06 & 1,85 & 1,77 \\
\hline Инициативность & 2,62 & 2,75 & 2,87 \\
\hline Семья & 3,03 & 2,82 & 2,77 \\
\hline Жизнь человека & 3,62 & 3,67 & 3,73 \\
\hline Традиция & 2,66 & 2,83 & 3,02 \\
\hline
\end{tabular}


Межпоколенческий ценностный анализ показал, что во всех возрастных группах интегрирующими компонентами являются жизнь человека и порядок, при этом в молодежной когорте в интегрирующее ядро вошла также свобода (табл. 6).

Особое внимание следует обратить на интегрирующий резерв молодежи, поскольку при опреде- ленных обстоятельствах именно этот блок, в настоящее время включающий стремление заботиться о своем здоровье и благополучии, помощь бедным и слабым даже в ущерб себе, хорошие семейные и дружеские отношения и содержательную, интересную работу, может стать интегрирующим для данной возрастной группы.

Интегрирующий и дифференцирующий кластеры

в разных возрастных группах

Table 6

Integrating and differentiating clusters in different age groups

\begin{tabular}{|c|c|c|c|c|}
\hline \multirow{2}{*}{\multicolumn{2}{|c|}{ Кластер }} & \multicolumn{3}{|c|}{ Возрастная группа } \\
\hline & & 18-29 лет & 30-49 лет & 50 лет и старше \\
\hline \multirow{7}{*}{ Интегрирующий } & \multirow{3}{*}{$\begin{array}{l}\text { Интегрирующее } \\
\text { ядро }\end{array}$} & Жизнь человека & Жизнь человека & Жизнь человека \\
\hline & & Порядок & Порядок & Порядок \\
\hline & & Свобода & Общительность & Властность \\
\hline & \multirow{4}{*}{$\begin{array}{l}\text { Интегрирующий } \\
\text { резерв }\end{array}$} & Благополучие & Жертвенность & Общительность \\
\hline & & Жертвенность & Свобода & Жертвенность \\
\hline & & Общительность & Властность & Благополучие \\
\hline & & Работа & Благополучие & Свобода \\
\hline \multirow{7}{*}{ Дифференцирующий } & \multirow{5}{*}{$\begin{array}{l}\text { Оппонирующий } \\
\text { дифференциал }\end{array}$} & Властность & Работа & Традиция \\
\hline & & Семья & Традиция & Работа \\
\hline & & Традиция & Семья & Инициативность \\
\hline & & Инициативность & Инициативность & Семья \\
\hline & & Нравственность & Нравственность & Нравственность \\
\hline & \multirow{2}{*}{$\begin{array}{l}\text { Конфликтогенная } \\
\text { периферия }\end{array}$} & Своевольность & Своевольность & Своевольность \\
\hline & & Независимость & Независимость & Независимость \\
\hline
\end{tabular}

При разработке программ государственной молодежной политики и патриотического воспитания необходимо учесть и определенные риски, и угрозы, связанные с социальной интеграцией молодежи в современное белорусское общество. При некоторых условиях это может проявиться в увеличении разрыва между двумя составляющими интеграционного механизма - включением молодежи в те или иные структуры и идентификацией с ними (как следствие, интеграция способна приобрести вынужденный характер, больше соответствующий механическому слиянию, нежели органически выстроенной связи); ускорении смены идентифика- ционных оснований, которые могут стать более «текучими»; активной локализации интеграционных процессов в рамках отдельных молодежных сообществ.

Данные обстоятельства могут привести к «исключению» молодого поколения из социума посредством активизации девиантных форм.

Таким образом, необходимо на государственном уровне в мониторинговом режиме отслеживать социальные настроения разных социальных групп белорусского общества в целях своевременного выявления рисков и угроз и формирования адекватной реакции на них.

\section{Библиографические ссылки}

1. Данилов АН. Новые геополитические реалии будущей цивилизации. Журнал Белорусского государственного университета. Социология. 2017;4:4-12.

2. Шавель СА. Общественная миссия социологии. Минск: Беларуская навука; 2010. 404 с. 
3. Ротман ДГ, Данилов АН, Булынко ДМ, Белов АА, Воднева АК, Соглаева ЛА. Ценностный мир современного человека: страны Восточного партнерства, Европейский союз и Россия в международных проектах по изучению ценностей. Булынко ДМ, Данилов АН, Правдивец ВВ, Ротман ДГ, редакторы. Минск: БГУ; 2016. 219 с.

4. Титаренко ЛГ. Образовательные услуги: рынок или образование? Журнал Белорусского государственного университета. Социология. 2019;3:58-64.

5. Лапин НИ. Кризисный социум в контексте социокультурных трансформаций. Мир России. 2000;3:3-47.

6. Лапин НИ. Структура ценностей россиян: всероссийский мониторинг и портрет региона. В: Когай ЕА, редактор. Опыт подготовки социокультурных портретов регионов России. Материалы III Всероссийской научно-практической конференщии; 25-28 сентября 2007 г.; Курск, Россия. Курск: Курский государственный университет; 2007. с. 43-55.

7. Лапин НИ. Функционально-ориентирующие кластеры базовых ценностей населения России и ее регионов. Социологические исследования. 2010;1:28-36.

\section{References}

1. Danilov AN. New geopolitical realities of the future civilization. Journal of the Belarusian State University. Sociology. 2017;4:4-12. Russian.

2. Shavel' SA. Obshchestvennaya missiya sotsiologii [Social mission of sociology]. Minsk: Belaruskaja navuka; 2010.404 p. Russian.

3. Rotman DG, Danilov AN, Bulynko DM, Belov AA, Vodneva AK, Soglaeva LA. Tsennostnyi mir sovremennogo cheloveka: strany Vostochnogo partnerstva, Evropeiskii soyuz i Rossiya $v$ mezhdunarodnykh proektakh po izucheniyu tsennostei [The value world of modern man: Eastern partnership countries, the European Union and Russia in international projects on the study of values]. Bulynko DM, Danilov AN, Pravdivets VV, Rotman DG, editors. Minsk: Belarusian State University; 2016.219 p. Russian.

4. Titarenko LG. Educational services: market or education? Journal of the Belarusian State University. Sociology. 2019;3: 58-64. Russian.

5. Lapin NI. [Crisis society in the context of socio-cultural transformations]. Mir Rossii. 2000;3:3-47. Russian.

6. Lapin NI. [The structure of Russians' values: all-Russian monitoring and a portrait of the region]. In: Kogay EA, editor. Opyt podgotovki sotsiokul'turnykh portretov regionov Rossii. Materialy III Vserossiiskoi nauchno-prakticheskoi konferentsii; 25-28 sentyabrya 2007 g.; Kursk, Rossiya [Experience of preparing socio-cultural portraits of Russian regions. Materials of the III All-Russian scientific-practical conference; 2007 September 25-28; Kursk, Russia]. Kursk: Kursk State University; 2007. p. 43-55. Russian.

7. Lapin NI. [Functionally oriented clusters of basic values of the population of Russia and its regions]. Sotsiologicheskie issledovaniya. 2010;1:28-36. Russian. 